
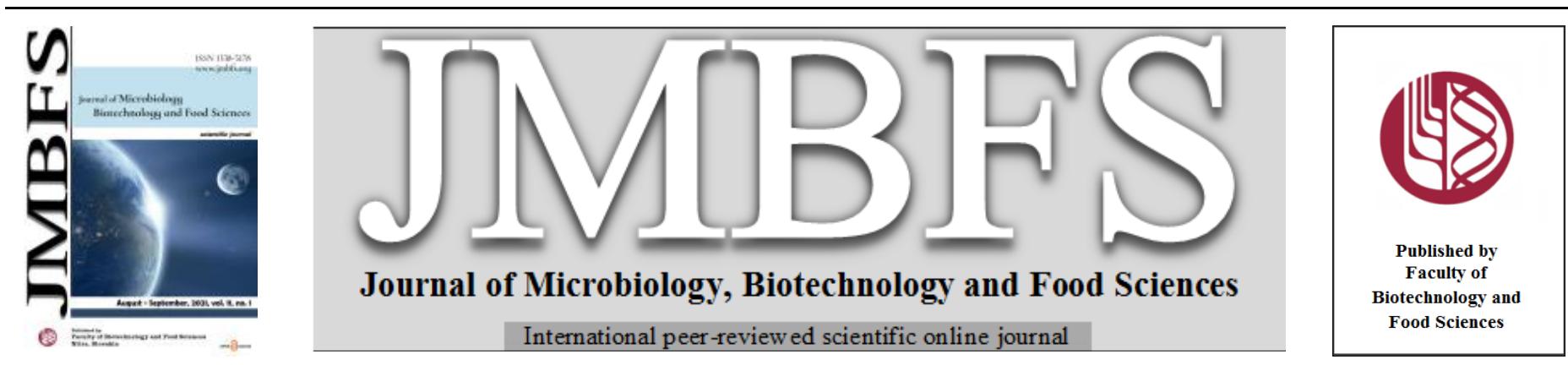

\title{
ANALYSIS OF NUTRITIONAL FACTORS INFLUENCING THE BIOSYNTHESIS OF AMYLOID BIOEMULSIFIER BE- AM1 APPLICABLE IN FOOD INDUSTRY
}

\author{
Anoop R. Markande* ${ }^{I}$ and Anuradha S. Nerurkar ${ }^{2}$
}

Address(es): A. R. Markande,

${ }^{1}$ Department of Biological Sciences, PD Patel Institute of Applied Sciences, Charotar University of Science and Technology, Changa, Gujarat 388421, INDIA, Phone number: +91-2697-265011/21.

${ }^{2}$ Department of Microbiology and Biotechnology centre, Faculty of Science, The Maharaja Sayajirao University of Baroda, Vadodara, Gujarat 390002, INDIA.

*Corresponding author: anoopmarkande@gmail.com, amarkande83@gmail.com

https://doi.org/10.15414/jmbfs.3170

\section{ARTICLE INFO}

Received 22. 5. 2020

Revised 18. 3. 2021

Accepted 24. 3. 2021

Published 1. 8. 2021

Regular article OPEN $\partial_{\text {ACCESS }}$

\section{ABSTRACT}

Thermostable glycoprotein amyloid bioemulsifier BE-AM1 was reported from Solibacillus silvestris AM1. S. silvestris could produce better BE-AM1 in 1\% inoculum size and 18h inoculum age. The BE-AM1 production by $S$. silvestris AM1 has been seen to be unaffected by amending the production and growth medium (Zobel Marine medium) with Carbon and Nitrogen sources. The effects of 16 nutrient factors (from ZM medium) were analyzed statistically by one factor at a time, Plackett-Burman and Response surface methodologies. Among the nutritive factors, yeast extract and peptone were found to be significant, increasing the production quantity of BE-AM1. The time course of production of BE-AM1 was affected significantly by altering the release of the biomolecule from the surface of the bacterium. This will be the first study to analyse the effect of factors influencing the production of industrially important functional amyloid protein from bacterial source having potential in environmental remediation and microbial interaction.

Keywords: Solibacillus, bioemulsifiers, amyloid, Plackett-Burman, response surface method

\section{INTRODUCTION}

The high molecular weight amphipathic biosurfactants are also termed as Bioemulsifiers which act as capsular polymers that are released into environment by the producing strain during growth (Amiriyan, et al. 2004). Special attributes such as lower level of toxicity and higher degradability have naturally increased research interest and consumer demand for natural alternatives like the bioemulsifiers. The release of biomolecules from bacteria are influenced by many factors (physical and nutritional) as seen in the production of bioemulsifiers from Corynebacterium sp. Pseudomonas sp. and Bacillus sp. influenced by carbon sources like hydrophobic solvents (alkanes) and water soluble substrates respectively (Amaral $\boldsymbol{e t}$ al., 2006). Amyloid proteins are the filamentous proteins reported to be made up of amphipathic nature that aggregate to form fibres. The amyloids produced due to the mis-folding of the cellular proteins in mammalian tissues (leading to amyloid fibre formation) resulting in neurodegenerative diseases in hosts are termed pathological amyloids while their purposeful production in fungi and bacteria for specific physiological functions of the producing cell are known as functional amyloids (Blanco, et al., 2012; Nielsen $r$ t al., 2011). The pathological amyloids (Soreghan, et al., 1994) and functional amyloids (Markande \& Nerurkar, 2016a) both have been reported for amphipathic nature and surfactant activities. A vast repertoire of biosurfactants have been reported with myriad of biomolecule contents and have the highest application food and allied industries (Markande \& Nerurkar, 2019). Nutrient parameters influencing the production of biosurfactants having industrial applications especially in petroleum and environmental have been consistently reported (Chai et al., 2019; Hema et al., 2019; Sharma \& Pandey, 2020; Somoza-Coutiño et al., 2020; Yaraguppi, et al., 2020). But the microbial amyloid bioemulsifiers have high applicability potential in food industry as they can be stable and can be extensively resistant to sterilization conditions.

Many polymeric carbohydrate based delivery systems (including cellulose, starch, pectin, chitosan, alginate, dextrin and cyclodextrins) are under study for utilization in food, pharmaceutical and other industries (Fathi et al., 2014). Selfassembling peptides having tailored structures possess extensive applications potential in nanotechnology (Wei et al., 2017). Amyloids like class I hydrophobins fall in the surface active agent category of amphipathic microbial functional amyloids that are extensively used in food industries (Morris, et al. 2011). Amyloids are potentially fundamental non-pathological protein folds being utilized by most living organisms (eukaryotic and prokaryotic) (Fowler et al., 2006).

Cao and Mezzenga, (2019) reviewed the various origins, formation conditions, chemical characters, potential applications and health implication of amyloid fibres from food proteins. Critical differences in packaging and assembly kinetics of pathological and functional amyloids dictates their potential uses in medicine and health-care (Fowler et al., 2006). The human microbiome associated amyloid proteins have the potential impact on amyloidogenesis of amyloid $\beta$ proteins in Alzheimer's disease and $\alpha$-synnuclein proteins of Parkinsons disease (Zhao and Lukiw, 2015; Sampson et al., 2020). For therapeutic intervention of neurodegenerative disease, a way to alter is to influence the microbial partners and their products like amyloid proteins nutritionally (Friedland and Chapman, 2017).

Solibacillus silvestris AM1 was recently reported to be differing in biochemical and utilization properties from the type strain HR3-23T (Markande, et al., 2018). S. silvestris AM1 was reported previously for the production of amyloid bioemulsifiers BE-AM1 having the ability to produce stable emulsions in aliphatic and aromatic hydrocarbons (Markande et al., 2013). This bioemulsifiers was further reported to be thermostable amyloid protein (Markande \& Nerurkar, 2016a) and capable of interacting with degraders for enhancement of remediation (Markande \& Nerurkar, 2016b). BE-AM1 production by $S$. silvestris AM1 was consistent in $\mathrm{pH}$ and $\mathrm{NaCl}$ concentrations variations, but was affected by temperature variation due its influence on bacterial growth. BE-AM1 production was also seen at oligotrophic conditions mimicking natural environments (Markande et al., 2018). Thus as the objective of present study were to elucidate the nutritive factors influencing the production of amyloid bioemulsifier BEAM1 using statistical methods like Plackett Burman and Response surface methodology. This will be the first report on the statistical analysis of nutrient influences on the production of bacterial functional amyloid having surfactant properties with potential applications in food industries.

\section{MATERIAL AND METHODS}

\section{Strain and assays}

Solibacillus silvestris AM1 (Accession number- MCC2096 at Microbial culture Collection Centre, NCCS, Pune, India) has been reported previously for production of amyloid bioemulsifiers- BE-AM1 only in Zobell Marine (ZM) 
medium (composition given in Table 1) showing enhanced thermos-stability (Markande \& Nerurkar, 2016a; Markande et al., 2013; Markande et al., 2018)

The production of amphipathic BE-AM1 was analysed by emulsification assay. Here, S. silvestris AM1 culture of 0.6 OD (A600) was grown in $50 \mathrm{ml}$ of ZM medium for $48 \mathrm{~h}\left(\right.$ at $30^{\circ} \mathrm{C}$ ) and cell free supernatant was mixed with paraffin light oil (MERCK, Germany) at 1:1 using a homogenizer. The emulsification produced was analysed by calculating \%EI as given by Markande $\boldsymbol{e t}$ al., (2013).

Table 1 Concentrations of the components used in OFAT and Plackett burman (PB) studies for the production of bioemulsifier by S. silvestris AM1

\begin{tabular}{|c|c|c|c|c|c|c|c|}
\hline \multirow{2}{*}{$\begin{array}{l}\text { Sl. } \\
\text { No. }\end{array}$} & \multirow[b]{2}{*}{ Components } & \multirow{2}{*}{$\begin{array}{c}\mathrm{ZM} \\
\text { medium }\end{array}$} & \multicolumn{3}{|c|}{ OFAT $(\mathrm{g} \%)$} & \multicolumn{2}{|c|}{ PB (g\%) } \\
\hline & & & Low & Medium & High & $\begin{array}{c}\text { High } \\
(+)\end{array}$ & $\begin{array}{l}\text { Low } \\
(-) \text { in }\end{array}$ \\
\hline 1 & Peptone & 0.5 & 0.25 & 0.5 & 0.75 & 3 & 0.3 \\
\hline 2 & $\begin{array}{c}\text { Yeast } \\
\text { extract }\end{array}$ & 0.1 & 0.05 & 0.1 & 0.15 & 1 & 0.1 \\
\hline 3 & $\mathrm{NaCl}$ & 1.95 & 0.97 & 1.95 & 2.9 & 2.5 & 1.5 \\
\hline 4 & $\mathrm{MgCl}_{2}$ & 0.88 & 0.44 & 0.88 & 1.32 & 1 & 0.25 \\
\hline 5 & $\mathrm{Na}_{2} \mathrm{SO}_{4}$ & 0.33 & 0.16 & 0.33 & 0.48 & 0.5 & 0.4 \\
\hline 6 & $\mathrm{CaCl}_{2}$ & 0.18 & 0.09 & 0.18 & 0.27 & 0.4 & 0.2 \\
\hline 7 & Fe-citrate & 0.01 & - & 0.01 & - & 0.01 & 0 \\
\hline 8 & $\mathrm{Na}_{2} \mathrm{HCO}_{3}$ & 0.016 & - & 0.016 & - & 0.016 & 0 \\
\hline 9 & $\mathrm{KCl}$ & 0.055 & - & 0.055 & - & 0.2 & 0.05 \\
\hline 10 & $\mathrm{KBr}$ & 0.008 & - & 0.008 & - & 0.04 & 0.008 \\
\hline 11 & $\mathrm{NaF}$ & 0.00024 & - & 0.00024 & - & 0.0024 & 0 \\
\hline 12 & $\mathrm{SrCl}_{2}$ & 0.0034 & - & 0.0034 & - & 0.0034 & 0 \\
\hline 13 & $\mathrm{H}_{3} \mathrm{BO}_{3}$ & 0.0022 & - & 0.0022 & - & 0.0022 & 0 \\
\hline 14 & $\mathrm{Na}_{2} \mathrm{SiO}_{3}$ & 0.0004 & - & 0.0004 & - & 0.004 & 0 \\
\hline 15 & $\left(\mathrm{NH}_{4}\right)_{2} \mathrm{NO}_{3}$ & 0.00016 & - & 0.00016 & - & 0.00016 & 0 \\
\hline 16 & $\mathrm{Na}_{2} \mathrm{HPO}_{4}$ & 0.0008 & - & 0.0008 & - & 0.0008 & 0 \\
\hline
\end{tabular}

\section{Bioemulsifier production}

\section{Inoculum size, inoculum age}

Bacterial culture was grown as described for \%EI. This overnight grown bacterial culture was pelleted and washed with phosphate buffered saline (PBS), adjusted to $0.6 \mathrm{OD}\left(6.3 \times 10^{7}\right.$ cells of $S$. silvestris AM1) and 1,2 and $3 \%$ inoculums were added into sterile $\mathrm{ZM}$ broth (in triplicates) and incubated for $48 \mathrm{~h}$ at $35^{\circ} \mathrm{C}$. Similarly, a loop full of inoculums was added into sterile $\mathrm{ZM}$ medium and incubated at $35^{\circ} \mathrm{C}$. After $6,12,18,24$ and $48 \mathrm{~h}$ of incubation, aliquotes were removed, pelleted and adjusted to 0.6 OD (using PBS) and 1\% was inoculated into $50 \mathrm{ml}$ sterile $\mathrm{ZM}$ medium in triplicates. After incubation, in both systems the culture was checked for OD and centrifuged for $10,000 \mathrm{rpm}$ for $10 \mathrm{~min}$. The cell free supernatant was checked for $\% \mathrm{EI}$

Analysis of influence of Galactose $(1,5,10$ and $15 \mathrm{mg} / \mathrm{ml})$ on BE-AM1 production by $S$. silvestris AM1

Galactose is a major carbohydrate that $S$. silvestris AM1 utilizes (Markande $\boldsymbol{e}$ al., 2018). Growth and production of BE-AM1 in cell bound and cell free form was checked in different concentrations of Galactose $(1,5,10,15 \mathrm{mg} / \mathrm{ml})$ in $\mathrm{ZM}$ salt solution. The inoculum was prepared as given for inoculum size experiments.

Statistical studies for medium component analysis

Madium: Standard Zobell-Marine (ZM 2116) medium was checked for the factors influencing the BE-AM1 production.

Table 2 Results of Plackett-Burman design for evaluating the components of ZM medium

\begin{tabular}{lccccccc}
\hline Components & High $(+)$ in $\mathbf{g} \%$ & Low $(-)$ in $\mathbf{g} \%$ & $\mathbf{E}(\mathbf{x i})$ & $\mathbf{t}(\mathbf{X i})$ & p-value & 1-pvalue & Confidence \\
\hline Peptone & 3 & 0.3 & 23.09 & 2.82 & 0.04 & 0.96 & 96.29 \\
Yeast extract & 1 & 0.1 & 28.91 & 3.53 & 0.02 & 0.98 & 98.33 \\
$\mathrm{Nacl}$ & 2.5 & 1.5 & -11.48 & 1.40 & 0.22 & 0.78 & 78.03 \\
$\mathrm{MgCl} 2$ & 1 & 0.25 & -14.37 & 1.75 & 0.14 & 0.86 & 86.03 \\
$\mathrm{Na} 2 \mathrm{SO} 4$ & 0.5 & 0.4 & 5.47 & 0.67 & 0.53 & 0.47 & 46.65 \\
$\mathrm{CaCl} 2$ & 0.4 & 0.2 & 6.26 & 0.76 & 0.48 & 0.52 & 52.08 \\
$\mathrm{Fe}-\mathrm{citrate}$ & 0.01 & 0 & 0.08 & 0.08 & 0.94 & 0.06 & 5.55 \\
$\mathrm{Na} 2 \mathrm{HCO} 3$ & 0.016 & 0 & 0.39 & 0.39 & 0.74 & 0.26 & 26.40 \\
$\mathrm{KCl}$ & 0.2 & 0.05 & 12.55 & 1.53 & 0.19 & 0.81 & 81.40 \\
$\mathrm{KBr}$ & 0.04 & 0.008 & 8.17 & 1.00 & 0.36 & 0.64 & 63.60 \\
$\mathrm{NaF}$ & 0.0024 & 0 & 0.17 & 0.17 & 0.88 & 0.12 & 12.18 \\
$\mathrm{SrCl} 2$ & 0.0034 & 0 & 0.00 & 0.00 & 1.00 & 0.00 & 0.01 \\
$\mathrm{H} 3 \mathrm{BO} 3$ & 0.0022 & 0 & 0.18 & 0.18 & 0.88 & 0.12 & 12.49 \\
$\mathrm{Na} 2 \mathrm{SiO} 3$ & 0.004 & 0 & 0.61 & 0.61 & 0.61 & 0.39 & 39.44 \\
$\mathrm{NH} 4 \mathrm{NO} 3$ & 0.00016 & 0 & 0.85 & 0.85 & 0.48 & 0.52 & 51.53 \\
$\mathrm{Na} 2 \mathrm{HPO} 4$ & 0.0008 & 0 & 0.44 & 0.44 & 0.71 & 0.29 & 29.45 \\
\hline
\end{tabular}

\section{One factor at a time (OFAT)}

Six macronutrients out of 16 total components of the $\mathrm{ZM}$ medium were studied by single factorial design. One independent macronutrient was taken with all the other components at their fixed level. Inoculum of 0.6 O.D was inoculated and the medium containing organism was incubated for $48 \mathrm{hrs}$ at $35^{\circ} \mathrm{C}$. After $48 \mathrm{hrs}$ the medium was centrifuged at $10,000 \mathrm{rpm}$ for $15 \mathrm{~min}$. The supernatant was further analyzed for emulsifying ability.

\section{Plackett Burman design}

To evaluate the relative importance of the components of the $\mathrm{ZM}$ medium, the Plackett-Burman experimental design (Srinandan, et al., 2010) was used. After OFAT studies, each variable was tested at 2 levels, a higher (+) and a lower (-) The 16 medium components were used as independent variables and three dummy variables were set to estimate the experimental error supplementary table 2 . The rows in supplementary table 2 shows experimental trials and each column represent different variables. The medium components in design were as given in table 1 . The results were tested in triplicates.

The effects of each variable was determined with the following equation
$E_{x i}=\left(\Sigma M_{i+}-\Sigma M_{i-}\right) / N$

where, Exi is the concentration effect of the tested variable, $\mathrm{Mi}+$ and $\mathrm{Mi}$ - are the emulsification indices from the trials where the variable (Xi) measured was present at high and low concentrations respectively and $\mathrm{N}$ is the number of trials (Srinandan et al., 2010). Since the objective of this study is to evaluate the relative effect of each variable, a significance level of less than 0.2 is acceptable. Significance of the triplicate values of each trial was calculated using Prism 5.0 software.

\section{Response surface methodology}

Response surface methodology using Box-Behnken design was used to estimate the nutritional factors important in BE-AM1 production using central composite design. The medium components used in the design were A: peptone $(3,1.65$ and $0.3 \mathrm{~g} \%), \mathrm{B}$ : yeast extract $(0.1,0.55$ and $1 \mathrm{~g} \%), \mathrm{C}: \mathrm{MgCl}_{2}(0.25,0.625$ and $1 \mathrm{~g} \%)$ and $\mathrm{D}: \mathrm{KCl}(0.05,0.125$ and $0.2 \mathrm{~g} \%)$. The behavior of the system was explained by, $Y=\beta_{o}+\Sigma \beta i x i+\Sigma \beta i j x i x j+\Sigma \beta i i x i^{2}$

where, $\mathrm{Y}$ is the predicted response, $\beta_{\mathrm{o}}$ is offset term, $\beta \mathrm{i}$ is a linear offset, $\beta \mathrm{ii}$ is squared offset and $\beta \mathrm{ij}$ is interaction effect. xi dimensionless coded value of $\mathrm{Xi}$. This equation was further solved by using the software Design-Expert (version 
8.0, Stat-Ease, Minneapolis, MN, USA) and the responses of the dependent variables were estimated.

\section{Critical micellar dilution}

Critical micellar dilution (CMD) indicates a minimum biosurfactant/bioemulsifier required for effective micelle formation, and is a measure of bioemulsifier concentration and its production. By diluting the crude amyloid BE-AM1 produced in ZM and AM1 medium (newly formulated combination of $\mathrm{ZM}$ medium components) with distilled water, the \%EI is measured. The dilution at which, \%EI starts to fall abruptly is the critical micellar dilution (CMD), where it is proportional to the amount of biosurfactant/bioemulsifier present in the sample (Markande et al., 2013).

\section{Influence of Peptone on production of BE-AM1 by S. silvestris AM1}

To check the effect of peptone (in low concentrations amended in ZM medium) on the production of amyloid BE-AM1 by S. silvestris AM1. The bacterium was inoculated in synthetic marine salt (ZM salts) solution containing different concentrations of protein $(0.5,1.0,1.5,2.0,2.5,5.0,7.5,10.0,12.5 \mathrm{mg} / \mathrm{ml}$ Peptone).

\section{Time course production of amyloid BE-AM1}

ZM medium and AM1 medium $\left(50 \mathrm{ml}\right.$ each) were inoculated with $6.3 \times 10^{7}$ (0.6OD) S. silvestris AM1 cells. The system was kept for incubation at $30^{\circ} \mathrm{C}$ Every hour, $2 \mathrm{ml}$ aliquots were taken out and centrifuged at 10,000 RPM for $10 \mathrm{~min}$. The cell pallet was given two washes with phosphate buffered saline (PBS; $140 \mathrm{mM} \mathrm{NaCl}, 2.7 \mathrm{mM} \mathrm{KCl}, 10 \mathrm{mM} \mathrm{Na} 2 \mathrm{HPO}_{4}$ and $1.8 \mathrm{mM} \mathrm{KH}_{2} \mathrm{PO}_{4}$ at $\mathrm{pH}$ 7.3 ) and $2 \mathrm{ml}$ cell suspension was made in PBS. Centrifugation supernatant and cell suspension were checked for $\% \mathrm{EI}\left(\mathrm{E}_{24}\right)$.

Time course of BE-AM1 production by $S$. silvestris AM1 in oligotrophic conditions of protein presence was checked by growing it in presence of 0.5 $\mathrm{mg} / \mathrm{ml}$ Peptone in ZM salt solution as given before at a sampling interval of every two hours from the point of inoculation.

\section{RESULTS AND DISCUSSION}

\section{Nutritional factors affecting amyloid BE-AM1 production}

The amyloids are extremely resistant proteins capable of withstanding physica (thermal), chemical and enzymatic denaturation (Gebbink, et al., 2005; Nielsen et al., 2011). These are extensively seen to be produced by microorganisms like fungi (Blanco et al., 2012), actinomycetes (Hammer, et al., 2008) and bacteria (Dueholm, et al., 2013) with specific functional and physiological intent (termed Functional amyloids) helping in microbial adhesion (Larsen et al., 2007; Lipke et al., 2012; Nielsen et al., 2011) capable of deciding microbial pathogenicity (Gebbink et al., 2005; Schwartz and Boles, 2013). Many microbial biosurfactants have been reported for applications in food industries (Markande \& Nerurkar, 2019).

The amyloid fibre formation during food processing are considered rare. But can get triggered into cross-reactive amyloids in gastric conditions or may provide raw materials for bacterial functional amyloids further enhancing human pathological amyloidogenesis (Lambrecht et al., 2019). Amyloidogenesis can be evolutionarily conserved ancient quaternary protein structure contributing to normal cell and tissue physiology (Fowler et al., 2006). Friedland and Chapman (2017) termed microbiota associated proteopathyand subsequent neuroinflamation as "mapranosis".

Although different from pathological amyloids, the food protein amyloids have uses as advanced biomaterials in medicine and tissue engineering, nanotechnology, environmental science, material sciences and in food sciences(Cao and Mezzenga, 2019). Food amyloids from whey, kidney bean, soy bean and egg white exhibited resistance to enzymatic digestion like Proteinase K treatment or Pancreatin (Lassé et al., 2016). Amyloid proteins have immense applications as effective gelling agents due to their functional surface chemistry (Lassé et al., 2016).

Although the southeast coast of India was relatively stable for last 50 years, their characteristics have been significantly changed by Indian ocean tsunami $\left(26^{\text {th }}\right.$ December 2004) (Senthilnathan, et al., 2012). The Vellar estuary (Tamil Nadu, India) present in this area has been extensively occupied by shrimp and prawn cultivation - enriching the water in the estuary with protein content. Here (Vellar estuary)- physical (temperature, $\mathrm{pH}$ and salinity) and chemical factors (carbon, nitrogen and phosphorus content) were reported to be undergoing distinct seasonal fluctuations and changes with respect to the textural type of the sediment (Sundaramanickam, et al., 2008).

The type strain of Solibacillus silvestrris was isolated from German forest soi (Rheims, et al., 1999) and was also reported for antineoplastic activities (Pettit et al., 2009). S. silvestris AM1 is an estuarine isolate from Perangipettai, Tamil $\mathrm{Nadu}$, India at Vellar estuary and differed from type strain in utilization studies and its ability to form amyloid BE-AM1 (Markande et al., 2018).
It was reported to be able to produce amyloid BE-AM1 only in ZM medium but differed in many utilization aspects from type strain HR3 $-23^{\mathrm{T}}$ (Markande $\boldsymbol{e t}$ al., 2013; Markande et al., 2018; Rheims, et al., 1999). As given in materials and methods, thirteen macro and micronutrients as salts in $\mathrm{ZM}$ medium make up around $3.4 \%$. Addition of $\mathrm{NaCl}$ to the medium in $\mathrm{g} \%$ increases the salt content to 3.55 to $8.55 \%$ respectively starting from 0\% amendment (Markande et al. 2018).

Inoculum age and inoculum size are the two factors usually known to affect the production of microbial surfactants like amyloid BE-AM1s. The size and age of the bacteria being added for production of a specific compound are important factors in deciding final yield of the product. $1 \mathrm{ml}$ of 0.6 O.D. of S. silvestris AM1 gave a better result than higher cell number. Similarly, addition of $18 \mathrm{~h}$ grown culture resulted in higher amyloid BE-AM1 production.
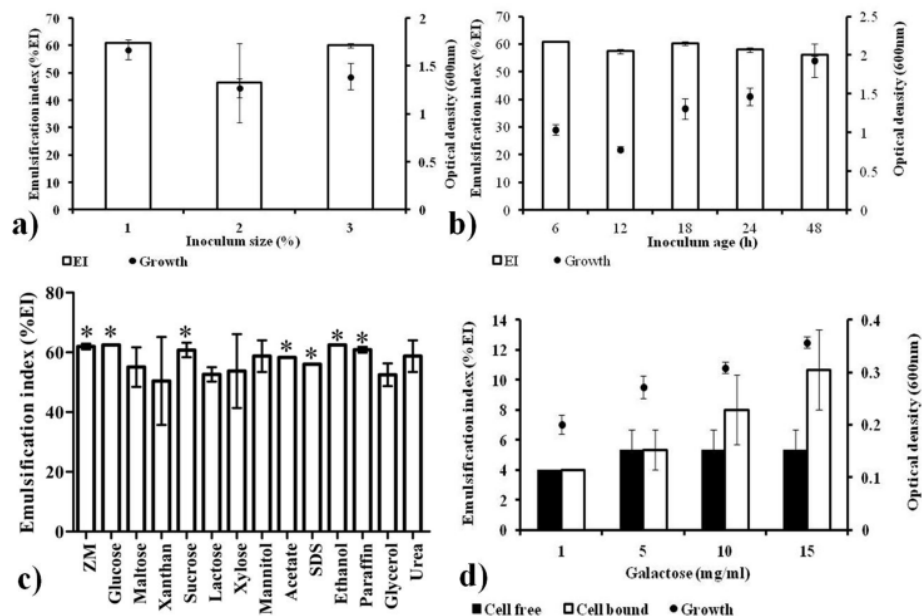

Figure 1 Effect of inoculum size (a) and inoculum age (b) on emulsification activity of $S$. silvestris AM1. $(n=3$; $p$ values, $\Delta=p<0.001$ and $*=p<0.05)$. (c) Emulsification index $(\% \mathrm{EI})$ of $S$. silvestris AM1 grown in ZM medium and its amendments with given sources $(*=p<0.001)$; (d) Effects of Galactose on growth and emulsification properties of $S$. silvestris AM1 ( $\mathrm{n}=3$; p-values: $*=\mathrm{p}<0.01)$.

Among the carbohydrates, S. silvestris AM1 utilizes galactose prominently (Table S1). As given in figure. 1d. Galactose, used as a sole carbon source, could promote the growth of $S$. silvestris AM1 with increased galactose concentration (0.2 to 0.36 O.D.), but gave negligible BE-AM1 production (2 - 5.3\% EI). S.silvestris AM1 has a limited ability to utilize the carbohydrates resulting in inability of glucose, sucrose and other sugars in increasing the amyloid BE-AM1 production. Addition of carbon sources to $\mathrm{ZM}$ medium did not induce amyloid BE-AM1 production. The lower bacterial growth in presence of some nutrient sources resulted in lower amyloid BE-AM1 production. Galactose being the major carbohydrate present in amyloid BE-AM1 produced (Markande et al. 2013), it was checked for increasing the amyloid BE-AM1 production. Presence of galactose marginally increased emulsification process. Human Pmel17 protein synthesizes tissue amyloid proteins in tight regulation to avoid toxicity which further has important roles in pigment production and activation of hemostatic system (Fowler et al., 2007). In pathological amyloidogenesis, salt ions are known to influence the course of misfolding of protein, its aggregation and amyloid formation (Dogra, et al., 2020).

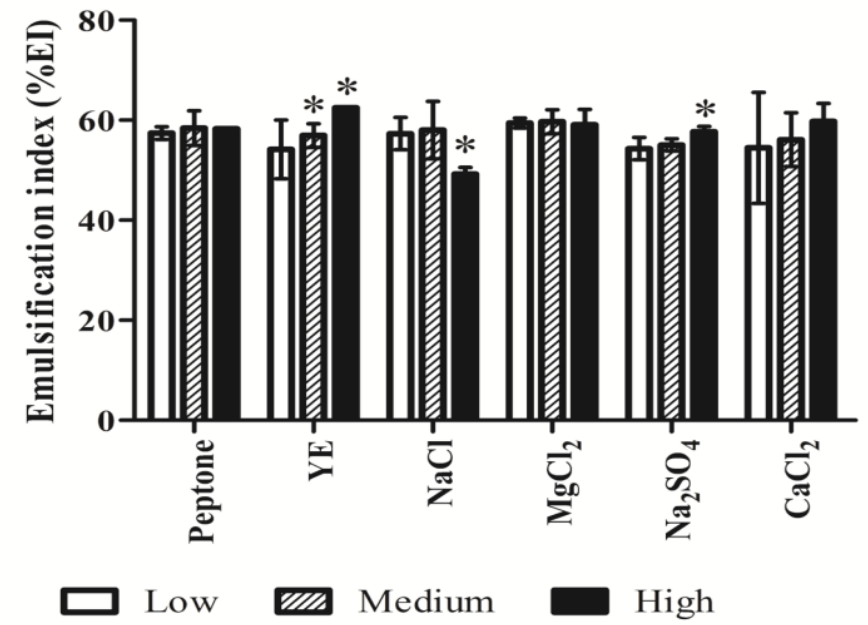

Figure 2 Effect of changing one factor at a time (OFAT) of the macronutrients from ZM medium on emulsification of $S$. silvestris AM1. (p-value, $*<0.001$ ). 
The amyloid BE-AM1 produced in the range of peptone and $\mathrm{MgCl}_{2}$ used in OFAT studies does not significantly affect the amyloid bioemulsifier production ( $\mathrm{pValue}=0.4$ and 0.9 respectively). 57-59\% EI was produced in presence of the two compounds. Changes in the concentration of YE affect the production of amyloid BE-AM1 significantly (pValue $<0.02$ ) with a range of 54-64\% EI. NaCl, $\mathrm{Na}_{2} \mathrm{SO}_{4}$ and $\mathrm{CaCl}_{2}$ showed varied effect on the production of amyloid BE-AM1 with the EI range between $49-59 \%$. As reported by many, the one factor at a time (OFAT) approach is time consuming but can be used for identifying critica components of the medium under study (Sivapathasekaran, et al., 2010; Srinandan et al., 2010). According to OFAT studies, the ranges of peptone and $\mathrm{MgCl}_{2}$ concentration taken have little significance on amyloid BE-AM1 production while yeast extract was found to be a significant factor. Using Plackett-burman design, the medium components giving highest emulsification $(\% \mathrm{EI}=68 \%$ in trial 9$)$ was achieved. Although the increase in emulsification is just for $10 \%$, from calculations, it can be stated that yeast extract is a significant factor which was also seen in OFAT studies (figure 2).
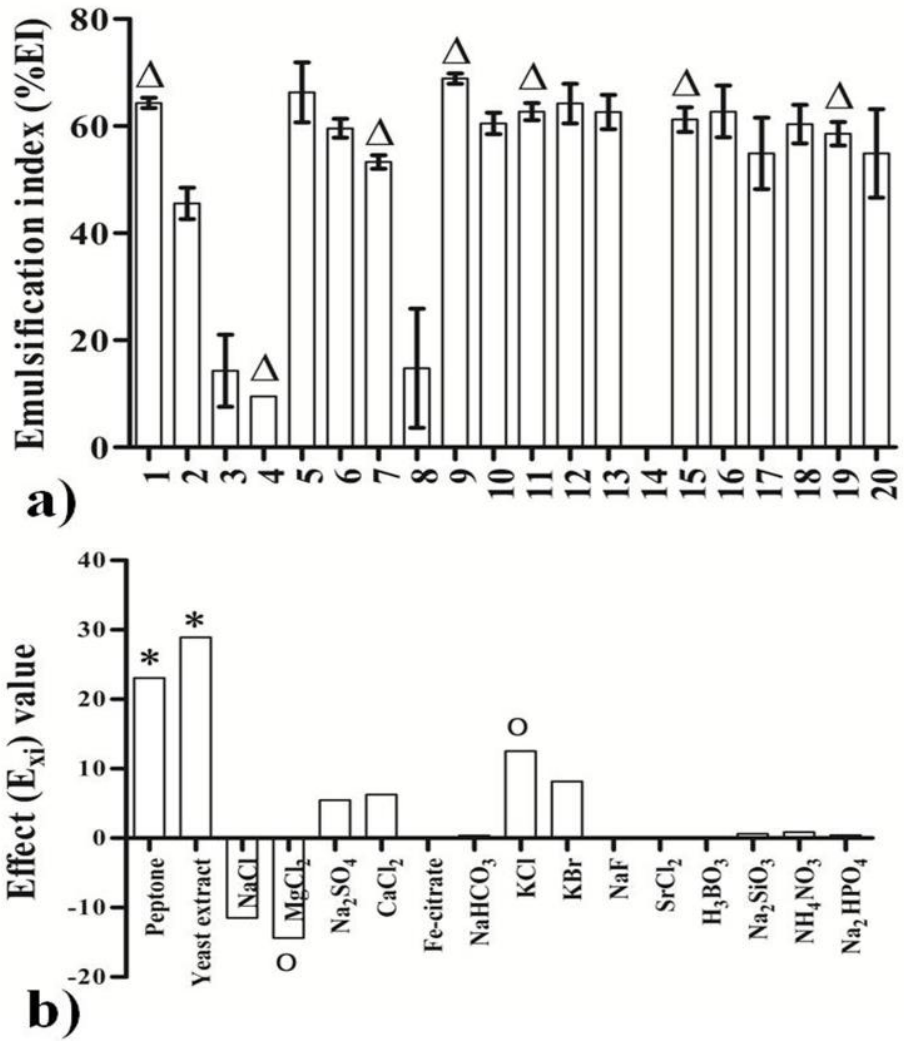

Figure 3 (a) The emulsification in presence of the 20 trial media of PlackettBurman design (p-value, $\Delta<0.001$ ); (b) Effects calculated for each of the components of $\mathrm{ZM}$ medium (p-value, $*<0.05, \mathrm{O}<0.2$ ).

When Plackett burman design was checked for effect of each constituents for amyloid BE-AM1 production (figure. $3 \mathrm{~b}$ ), effects of peptone, yeast extract were highest in the positive side with $\mathrm{KCl}$, while $\mathrm{MgCl} 2$ showed highest negative effect for amyloid BE-AM1 production. Although it is known that less than $5 \%$ variation in the confidence of the matrix is sufficient, the amyloid BE-AM studies with matrix analysis of Plackett-Burman design is robust and it rarely shows the probability of observations arising more than $20 \%$ of the confidence is rarely due to chance. Hence $\mathrm{MgCl}_{2}$ and $\mathrm{KCl}$, both giving significance $\mathrm{p}$ value $<0.2$ were selected for further studies.

Industrial processing may induce food protein to re-fold to form effective amyloid monomers capable of forming fibres as in case of boiling of hen egg white (Monge-Morera et al., 2020). Manipulation of protein processing conditions for core regions of food protein which fold into amyloids and further promote sequential and ordered aggregation can enhance and control food functionality. Thus amyloid fibril formation in food protein can help tailor aggregation and fibril-techno functionality (Jansen et al., 2019).

Sundaramanickam et al., (2008) reported the rapid increase of shrimp farms (42 till 1995, covering an area of 150ha.) along the vellar estuary. The feed pellet given to the shrimps have become the major source of eutrophication in the estuary. This release of used water from the shrimp farms into the backwaters, estuaries and mangroves affecting the biological communities and has become a major concern for environmentalists (Sundaramanickam et al., 2008). To study the significant component of the Zobell-marine medium, Plackett-Burman design and Response surface methodology were used. The amyloid BE-AM1 production, quantified as emulsification index (\%EI) from the cell-free supernatant of the media trials are given in table 2. As shown in figure. 3a, trial 9 showed highest EI of $68.9 \%$ and trial 5 showed $66.3 \%$ EI. Trials 1, 11, 12, 13, 15 ,
16 and 18 gave 60-64\% EI, nearer to ZM medium's $62.5 \%$ EI. Trial 4 gave lowest EI of $9.5 \%$. The four components of ZM medium shortlisted for their significant positive influence in production of amyloid BE-AM1 by $S$. silvestris AM1 were analyzed using Box-Behnken design in Design Expert 8.0 software. Similar to Plackett-Burman design, peptone and yeast extract were found to be the most significant factors among the four components shortlisted from Zobell marine medium. Although the four factors did not interact for amyloid BE-AM1 production, they interacted significantly for surface tension reduction (data not shown). The ZM medium and its four components making up AM1 medium were checked for amount of amyloid BE-AM1 release and were found to be more as the emulsification activity is seen even after 1000times dilution. Design-Expert@ Software

Factor Coding: Actual

- Design Points

66.66

0

$\mathrm{X} 1=\mathrm{A}:$ Pep

$\mathrm{X} 2=\mathrm{B}: \mathrm{YE}$

Actual Factors

C: $\mathrm{MgCl} 2=0.60$

D: $\mathrm{KCl}=0.13$

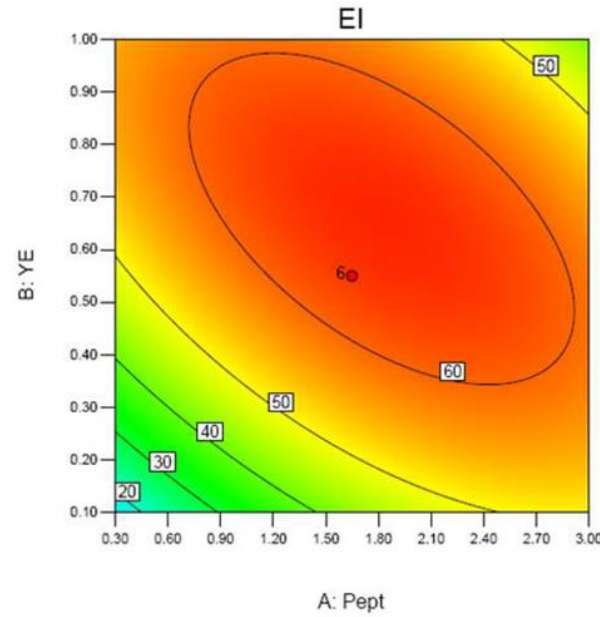

Figure 4 Contour graph of analysis of Emulsification index by Design Expert software version 8.0 of StatEase

Effects (Exi) of the components of ZM medium were calculated as given before and are given in figure. $3 \mathrm{~b}$. Positive Exi value of the variable is considered to be positively influencing $S$. silvestris Am1 in higher BE-AM1 production among the ranges of the concentrations taken, and negative result shows its positive influence in lower concentrations. Peptone and YE influenced significantly on the production of amyloid BE-AM1 $(\mathrm{p}<0.05)$ while $\mathrm{MgCl}_{2}$ and $\mathrm{KCl}$ influence with lower significance $(\mathrm{p}<0.2)$. As shown in figure. $3 \mathrm{~b}$ peptone, $\mathrm{YE}$ and $\mathrm{KCl}$ showed positive Exi values. $\mathrm{MgCl}_{2}$ showed negative Exi value showing its influence in enhancing the production of amyloid BE-AM1 by S. silvestris in its lower concentrations taken for this test (table 2).

Design Expert version 8.0 of StatEase was used to build Box-Behnken design and to analyze the results obtained. These components were studied for their interactions and use of this model for higher production of amyloid BE-AM1 After the analysis, the response yielded a linear model as there was no interaction seen among the components for amyloid BE-AM1 production. Peptone and yeast extract were found to be most significant components influencing the production with p-values of $<0.0001$ and 0.0044 respectively giving the hot zone as given in figure. 4. Since F-value of model was found to be 10.22 , there is only a $0.01 \%$ chance that a 'model F-value' this large could occur due to noise. The lack of fit value for the model was not significant $(\mathrm{p}=0.7494)$. Thus, there is a $74.94 \%$ chance that a lack of fit F-value of 0.68 could occur due to noise or pure error. Thus the model and its terms were found to be significant.

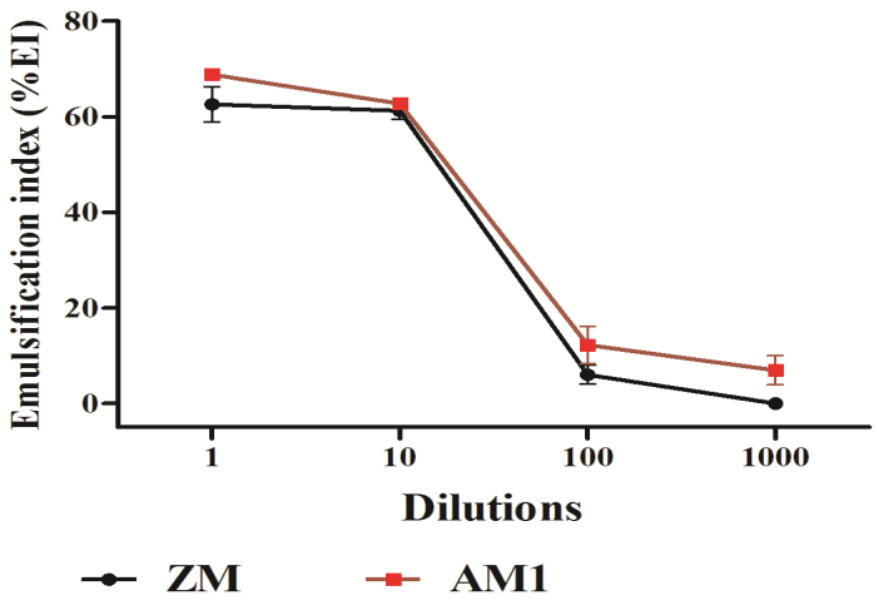

Figure 5 Critical micellar dilution (CMD) of bioemulsifier produced in $\mathrm{ZM}$ medium and optimized AM1 medium 
The important nutritional factors shown by Placket-Burman design for amyloid BE-AM1 production were compared with $\mathrm{ZM}$ by checking for CMD in the two media. Production of amyloid BE-AM1 was unaffected in both the media with CMD showing slight defferences (figure. 5). In presence of minimal nutritional factors (in medium AM1), S. silvestris AM1 produced $68 \% \mathrm{EI}$ as compared to $62 \% \mathrm{EI}$ in $\mathrm{ZM}$ medium, retaining $9.7 \%$ more emulsification activity with after 1000 times dilution. Amyloid protein formation was shown to be enhanced in presence of hydrolysed proteins (Lambrecht et al., 2019).

\section{Time course of BE-AM1 release}

At $12 \mathrm{~h}, \mathrm{~S}$. silvestris AM1 reaches stationary growth and produced amyloid BEAM1 without hydrocarbon-induction. The bacterium exhibits cell-bound emulsification activity (\%EI) after $6 \mathrm{~h}$ growth (mid-log phase) while cell free emulsification activity can be detected after 16h, when the culture's growth is in a stationary phase (data not shown). Emulsan is known to accumulate on the cellsurface of A. calcoaceticus RAG-1 as a mini-capsule during logarithmic phase of growth and like many other extracellular polysaccharides, it is produced after the cells reach stationary phase, similar results were observed in case of amyloid BEAM1 production in S. silvestris AM1. Bacterial amyloids have been reported for their amphipathic nature and surface adherence properties (Markande $\&$ Nerurkar, 2016a). As the lesser significant components namely of ZM medium were eliminated in the AM1 medium, the amyloid BE-AM1 release by the bacterium is changed effectively. Release of cell-free amyloid BE-AM1 is decreased by $8 \mathrm{~h}$ (figure. 6), while the lag phase of the bacterium is increased by $2 \mathrm{~h}$. The cell bound emulsifier is produced at higher amounts in oligotrophic conditions (figure. 6). In natural conditions, with competition for nutrients, bacteria produce more cell-bound amyloid BE-AM1 than cell free.

Presence of optimum environmental (including intrinsic and extrinsic) and nutritive factors like aminoacids and peptides prone to amyloidogenesis can lead to food protein conversion to amyloid fibrils. This has been extensively studied for egg, cereals, milk and legume proteins (Jansens et al., 2019; Lambrecht et al., 2019).
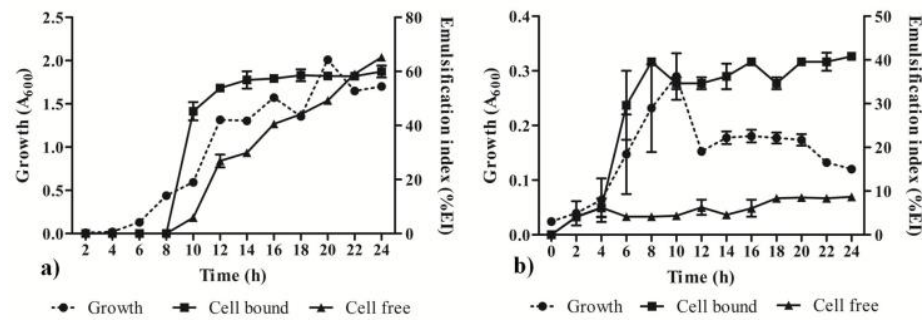

Figure 6 Time course of bioemulsifier production in ZM and AM1 media

As shown in figure. $6 \mathrm{a}$, the cell-bound emulsification of $S$. silvestris AM1 starts to increase after $8^{\text {th }}$ hour in AM1 medium as compared to ZM medium. But the Cell-free amyloid BE-AM1 release also starts simultaneously with cell-bound. Thus, in presence of production enhancing medium components, the cell-bound amyloid BE-AM1 expression is delayed by $4 \mathrm{~h}$, but, cell-free amyloid BE-AM1 release is preponed by $6 \mathrm{~h}$. The correlation of growth in AM1 and in ZM media showed There was higher correlation of growth of S. silvestris AM1 in ZM and AM1 media with $r^{2}=0.895$. Fowler et al., (2006) reported the carefully orchestrated amyloidogenesis and secretion pathway in animal tissues which can be used to study both amyloid pathology and melanin formation.

In comparison to growth in ZM medium or AM1 medium, the growth of $S$. silvestris AM1 was significantly low $(\mathrm{p}<0.0001)$ in oligotrophic conditions After $12^{\text {th }} \mathrm{h}$ of growth, the growth dropped drastically. Highest cell bound $\% \mathrm{EI}$ observed in oligotrophic conditions was $41 \%$ as compared to $62.5 \%$ and $68 \%$ in $\mathrm{ZM}$ and AM1 medium. The cell free emulsification was least in comparison with AM1 and ZM medium even after 24h. The cell free emulsification shown is at the basal level, but enough for the emulsification activity to be visible (that is above the CMC level).

The ability of food proteins for fibrillation has been progressively recognized as an appealing strategy for broadening and improvement of food protein functionality as seen in case of heat induced amyloid- albumin protein (Cao and Mezzenga, 2019; Pearce et al., 2007). Pérez-Tavarez et al., (2020) reported the assembly of animal food allergens into amyloids in gastric-like environments and further interaction with $\mathrm{IgE}$. Due to current understanding of the interaction of non-identical amyloids leading to pathological amyloidogenesis, this can prove to be interesting phenomenon to persue for further research. Cao and Mezzenga, (2019) studied the uses of food protein amyloids as Thickening and gelling agents, surface active agents, nutrient-drug carriers, packaging materials, antioxidents and as antimicrobial agents.

Evidences are accumulating for the cross-interactions of bacterial functional amyloids with pathological amyloids like $\alpha$-synnuclein enhancing neurodegenerative diseases. While humans code almost 30 proteins with amyloidogenic properties, their cross-interaction with extensively studied functional amyloids from gut-associated bacteria can trigger amyloid accumulation and neurodegeneration (Sampson et al., 2020).

\section{CONCLUSION}

Recently, bacterial functional amyloids from gut microbiota have been implicated inn enhancement of pathological amyloid progression of neurodegenrative diseases. Hence, studies on bacterial functional amyloid production and the fators thereby influencing this amyloidogenesis has increased in importance. In present work, S. silvestris AM1 did not utilize major carbon sources for its BE-AM1 production, but could use basic protein sources like BSA and peptone for significant amyloid production. The unique ability of $S$. silvestris AM1 and factors influencing its amyloid bioemulsifier production can be further used biotechnologically for studying other strains for various biomolecule production of industrial potential.

Acknowledgments: AM is grateful to University Grants Commission (UGC), India for the financial grant.

\section{REFERENCES}

Amaral, P. F. F., Silva, J. M., Lehocky, M., Barros-timmons, A. M. V, Coelho, M. A. Z., Marrucho, I. M., \& Coutinho, J. A. P. (2006). Production and characterization of a bioemulsifier from Yarrowia lipolytica. Process Biochemistry, 41, 1894-1898. https://doi.org/10.1016/j.procbio.2006.03.029 Amiriyan, A., Assadi, M. M., Saggadian, V. A., \& Noohi, A. (2004). Bioemulsan Production by Iranian Oil Reservoirs. Health (San Francisco), 1(2), 28-35 Retrieved from http://ijehse.tums.ac.ir/index.php/jehse/article/viewFile/14/13 Blanco, L. P., Evans, M. L., Smith, D. R., Badtke, M. P., \& Chapman, M. R. (2012). Diversity , biogenesis and function of microbial amyloids. Trends in Microbiology, 20(2), 66-73. https://doi.org/10.1016/j.tim.2011.11.005

Cao, Y., \& Mezzenga, R. (2019). Food protein amyloid fibrils: Origin, structure, formation, characterization, applications and health implications. Advances in Colloid and Interface Science, 269, 334-356. https://doi.org/10.1016/j.cis.2019.05.002

Chai, T., Yan, H., Zhang, Z., Xu, M., Wu, Y., Jin, L., ... Fu, H. (2019). Optimization of enhanced ultrafiltration conditions for $\mathrm{Cd}$ with mixed biosurfactants using the Box-Behnken response surface methodology. Water (Switzerland), 11(3). https://doi.org/10.3390/w11030442

Dogra, P., Roy, S. S., Joshi, A., Mukhopadhyay, S., Roy, S. S., Joshi, A., \& Mukhopadhyay, S. (2020). Hofmeister Ions Modulate the Autocatalytic Amyloidogenesis of an Intrinsically Disordered Functional Amyloid Domain via Unusual Biphasic Kinetics. Journal of Molecular Biology, 432(23), 6173-6186. https://doi.org/10.1016/j.jmb.2020.10.015

Dueholm, M. M. S., Otzen, D., \& Nielsen, P. P. H. (2013). Evolutionary insight into the functional amyloids of the pseudomonads. PloS One, 8(10), e76630 https://doi.org/10.1371/journal.pone.0076630

Fathi, M., Martín, Á., \& McClements, D. J. (2014). Nanoencapsulation of food ingredients using carbohydrate based delivery systems. Trends in Food Science and Technology, 39(1). 18-39. https://doi.org/10.1016/j.tifs.2014.06.007

Fowler, D. M., Koulov, A. V, Alory-Jost, C., Marks, M. S., Balch, W. E., \& Kelly, J. W. (2006). Functional Amyloid Formation within Mammalian Tissue. PLoS Biology, 4(1), 2-9. https://doi.org/10.1371/journal.pbio.0040006

Fowler, D. M., Koulov, A. V, Balch, W. E., \& Kelly, J. W. (2007). Functional amyloid--from bacteria to humans. Trends in Biochemical Sciences, 32(5), 217 224. https://doi.org/10.1016/j.tibs.2007.03.003

Friedland, R. P., \& Chapman, M. R. (2017). The role of microbial amyloid in neurodegeneration. PLoS Pathogens, 13(12), 1-12. https://doi.org/10.1371/journal.ppat.1006654

Gebbink, M. F., Claessen, D., Bouma, B., Dijkhuizen, L., \& Wösten, H. A (2005). Amyloids - a functional coat for microorganisms. Nature Reviews, 3(4), $333 . \quad$ Retrieved from http://search.proquest.com/openview/a97875e7d616ccd4db6c0d4720db81b1/1?p q-origsite $=$ gscholar \&cbl $=27584$

Hammer, N. D., Wang, X., McGuffie, B. A., \& Chapman, M. R. (2008). Amyloids: friend or foe? Journal of Alzheimer's Disease, 13(4), 407-419. Retrieved from http://content.iospress.com/articles/journal-of-alzheimersdisease/jad00765

Hema, T., Seghal Kiran, G., Sajayyan, A., Ravendran, A., Gowtham Raj, G., \& Selvin, J. (2019). Response surface optimization of a glycolipid biosurfactant produced by a sponge associated marine bacterium Planococcus sp. MMD26. Biocatalysis and Agricultural Biotechnology, 18(December 2018), 101071. https://doi.org/10.1016/j.bcab.2019.101071

Jansens, K. J. A., Lambrecht, M. A., Rombouts, I., Monge Morera, M., Brijs, K., Rousseau, F., ... Delcour, J. A. (2019). Conditions Governing Food Protein Amyloid Fibril Formation-Part I: Egg and Cereal Proteins. Comprehensive Reviews in Food Science and Food Safety, 18(1), 1256-1276. https://doi.org/10.1111/1541-4337.12462

Jansens, K. J. A., Rombouts, I., Grootaert, C., Brijs, K., Van Camp, J., Van der Meeren, P., ... Delcour, J. A. (2019). Rational Design of Amyloid-Like Fibrillary 
Structures for Tailoring Food Protein Techno-Functionality and Their Potential Health Implications. Comprehensive Reviews in Food Science and Food Safety, 18(1), 84-105. https://doi.org/10.1111/1541-4337.12404

Lambrecht, M. A., Jansens, K. J. A., Rombouts, I., Brijs, K., Rousseau, F., Schymkowitz, J., \& Delcour, J. A. (2019). Conditions Governing Food Protein Amyloid Fibril Formation. Part II: Milk and Legume Proteins. Comprehensive Reviews in Food Science and Food Safety, 18(1), 1277-1291. https://doi.org/10.1111/1541-4337.12465

Lassé, M., Ulluwishewa, D., Healy, J., Thompson, D., Miller, A., Roy, N., .. Gerrard, J. A. (2016). Evaluation of protease resistance and toxicity of amyloidlike food fibrils from whey, soy, kidney bean, and egg white. Food Chemistry, 192, 491-498. https://doi.org/10.1016/j.foodchem.2015.07.044

Larsen, P., Nielsen, J. L., Dueholm, M. S., Wetzel, R., Otzen, D., \& Nielsen, P. H. H. (2007). Amyloid adhesins are abundant in natural biofilms. Environmenta Microbiology, 9(12), 3077-3090. https://doi.org/10.1111/j.1462 2920.2007.01418.x

Lipke, P. N., Garcia, M. C., Alsteens, D., Ramsook, C. B., Klotz, S. A., \& Dufrêne, Y. F. (2012). Strengthening relationships: amyloids create adhesion nanodomains in yeasts. Trends in Microbiology, 20(2), 59-65. https://doi.org/10.1016/j.tim.2011.10.002

Markande, A. R., \& Nerurkar, A. S. (2016a). Bioemulsifier (BE-AM1) produced by Solibacillus silvestris AM1 is a functional amyloid that modulates bacterial cell-surface properties. Biofouling, 32(10), 1153-1162. https://doi.org/10.1080/08927014.2016.1232716

Markande, A. R., \& Nerurkar, A. S. (2016b). Microcosm-based interaction studies between members of two ecophysiological groups of bioemulsifier producer and a hydrocarbon degrader from the Indian intertidal zone. Environmental Sciences and Pollution Research, 1-10. https://doi.org/10.1007/ $\underline{\text { s11356-016-6625-1 }}$

Markande, A.R., Acharya, S. R., Nerurkar, A. S., Anoop R. Markande, Shashikanth R. Acharya, \& Anuradha S. Nerurkar. (2013). Physicochemica characterization of a thermostable glycoprotein bioemulsifier from Solibacillus silvestris AM1. Process Biochemistry, 48(11), 1800-1808. https://doi.org/10.1016/j.procbio.2013.08.017

Markande, Anoop R., \& Nerurkar, A. S. (2019). Microbial Bioemulsifiers \& Their Roles in the Natural Environment. In V. Katiyar \& A. Joshi (Eds.), MICROBIAL RESEARCH: An Overview (pp. 1-21). New Delhi: I . K International Publishing House Pvt . Ltd

Markande, Anoop R., Vemuluri, V. R., Shouche, Y. S., \& Nerurkar, A. S. (2018) Characterization of Solibacillus silvestris strain AM1 that produces amyloid bioemulsifier. Journal of Basic Microbiology, 58(6), 523-531. https://doi.org/10.1002/jobm.201700685

Monge-Morera, M., Lambrecht, M. A., Deleu, L. J., Gallardo, R., Louros, N. N., De Vleeschouwer, M., ... Delcour, J. A. (2020). Processing Induced Changes in Food Proteins: Amyloid Formation during Boiling of Hen Egg White. Biomacromolecules, $21(6)$,

2218-2228

https://doi.org/10.1021/acs.biomac.0c00186

Morris, V. K., Ren, Q., Macindoe, I., Kwan, A. H., Byrne, N., \& Sunde, M. (2011). Recruitment of class I hydrophobins to the air:Water interface initiates a multi-step process of functional amyloid formation. Journal of Biological Chemistry, 286(18), 15955-15963. https://doi.org/10.1074/jbc.M110.214197

Nielsen, P. H., Dueholm, M. S., \& Thomsen, T. R. (2011). Functional Bacteria Amyloids in Biofilms. In U. S. Hans-Curt Flemming, Jost Wingender (Ed.), Biofilm Highlights (pp. 41-62). Berlin Heidelberg: Springer-Verlag. https://doi.org/10.1007/978-3-642-19940-0

Pearce, F. G., Mackintosh, S. H., \& Gerrard, J. A. (2007). Formation of amyloidlike fibrils by ovalbumin and related proteins under conditions relevant to food processing. Journal of Agricultural and Food Chemistry, 55(2), 318-322 https://doi.org/10.1021/jf062154p

Pérez-Tavarez, R., Castellanos, M., Loli-Ausejo, D., Pedrosa, M., Hurtado, J. L., Rodriguez-Pérez, R., \& Gasset, M. (2020). Animal food allergens share the formation of IgE-binding amyloids. Allergies, 1(2), 5-9. https://doi.org/10.20944/preprints202007.0359.v1

Pettit, G. R., Knight, J. C., Herald, D. L., Pettit, R. K., Hogan, F., Mukku, V. J., ... Chapuis, J. C. (2009). Antineoplastic agents. 570. Isolation and structure elucidation of bacillistatins 1 and 2 from a marine Bacillus silvestris. Journal of Natural Products, 72(3), 366-371. http://pubs.acs.org/doi/abs/10.1021/np800603u

Rheims, H, Frühling, A., Schumann, P., Rohde, M., \& Stackebrandt, E. (1999) Bacillus silvestris sp. nov., a new member of the genus Bacillus that contains lysine in its cell wall. International Journal of Systematic and Evolutionary Microbiology, 49(2), 795-802. $\quad$ Retrieved from http://ijs.microbiologyresearch.org/content/journal/ijsem/10.1099/00207713-49$\underline{2-795}$

Rheims, Holger, Fruhling, A., Schumann, P., \& Rohde, M. (1999). Bacillus silvestris sp . nov ., a new member of the genus Bacillus that contains lysine in its cell wall. International Journal of Systematic Bacteriology, (1 999), 795-802.

Sampson, T. R., Challis, C., Jain, N., Moiseyenko, A., Ladinsky, M. S., Shastri, G. G., ... Mazmanian, S. K. (2020). A gut bacterial amyloid promotes a- synuclein aggregation and motor impairment in mice. ELife, 9(e53111), 1-19. https://doi.org/10.7554/eLife.53111

Schwartz, K., \& Boles, B. R. (2013). Microbial amyloids--functions and interactions within the host. Current Opinion in Microbiology, 16(1), 93-99. https://doi.org/10.1016/j.mib.2012.12.001

Senthilnathan, L., Nobi, E. P., Thangaradjou, T., \& Kannan, L. (2012). Longtime shoreline monitoring of the vellar estuarine complex, southeast coast of India: Using multispectral satellite data. Journal of Earth Science, 23(6), 900907. https://doi.org/10.1007/s12583-012-0304-Z

Sharma, S., \& Pandey, L. M. (2020). Production of biosurfactant by Bacillus subtilis RSL-2 isolated from sludge and biosurfactant mediated degradation of $\begin{array}{llll}\text { oil. Bioresource } & \text { Technology, } & \text { 307(February), }\end{array}$ https://doi.org/10.1016/j.biortech.2020.123261

Sivapathasekaran, C., Mukherjee, S., Ray, A., Gupta, A., \& Sen, R. (2010) Artificial neural network modeling and genetic algorithm based medium optimization for the improved production of marine biosurfactant. Bioresource Technology, 101(8), 2884-2887. https://doi.org/10.1016/j.biortech.2009.09.093

Somoza-Coutiño, G., Wong-Villarreal, A., Blanco-González, C., Pérez-Sariñana, B., Mora-Herrera, M., Mora-Herrera, S. I., ... Yañez-Ocampo, G. (2020). A bacterial strain of Pseudomonas aeruginosa B0406 pathogen opportunistic, produce a biosurfactant with tolerance to changes of $\mathrm{pH}$, salinity and $\begin{array}{llll}\text { temperature. } & \text { Microbial } & \text { Pathogenesis, } & 139,\end{array}$ https://doi.org/10.1016/j.micpath.2019.103869

Soreghan, B., Kosmoski, J., \& Glabe, C. (1994). Surfactant properties of Alzheimer's A beta peptides and the mechanism of amyloid aggregation. Journal of Biological Chemistry, 269(46), 28551-28554. Retrieved from http://www.jbc.org/content/269/46/28551.short

Srinandan, C., Jadav, V., Cecilia, D., \& Nerurkar, A. (2010). Nutrients determine the spatial architecture of Paracoccus sp. biofilm. Biofouling, 26(4), 449-459. Retrieved

http://www.tandfonline.com/doi/abs/10.1080/08927011003739760

Sundaramanickam, A., Sivakumar, T., Kumaran, R., Ammaiappan, V., \& Velappan, R. A comparative study of physico-chemical investigation along Parangipettai and Cuddalore coast.pdf, 1 Journal of Environmental Science and $\begin{array}{lllll}\text { Technology } & \S & \text { (2008). } & \text { Retrieved }\end{array}$ http://www.docsdrive.com/pdfs/ansinet/jest/2008/1-10.pdf

Wei, G., Su, Z., Reynolds, N. P., Arosio, P., Hamley, I. W., Gazit, E., \& Mezzenga, R. (2017). Self-assembling peptide and protein amyloids: From structure to tailored function in nanotechnology. Chemical Society Reviews, 46(15), 4661-4708. https://doi.org/10.1039/c6cs00542j

Yaraguppi, D. A., Bagewadi, Z. K., Muddapur, U. M., \& Mulla, S. I. (2020). Response surface methodology-based optimization of biosurfactant production from isolated Bacillus aryabhattai strain ZDY2. Journal of Petroleum Exploration and Production Technology, (0123456789). https://doi.org/10.1007/s13202-020-00866-9

Zhao, Y., \& Lukiw, W. J. (2017). Microbiome-generated amyloid and potentia impact on amyloidogenesis in Alzheimer's disease (AD). Physiology \& Behavior, 176(3), 139-148. Retrieved from http://www.jnsci.org/index.php?journal=nsci\&page=article\&op=view\&path\%5B $\% 5 \mathrm{D}=138$ 
Supplementary table.

Supplementary table 1: Plackett - Burman design for 16 medium components of ZM

\begin{tabular}{|c|c|c|c|c|c|c|c|c|c|c|c|c|c|c|c|c|c|c|c|}
\hline \multirow[b]{2}{*}{ Trials } & \multicolumn{19}{|c|}{ Variables } \\
\hline & $\mathrm{X} 1$ & $\mathrm{X} 2$ & $\mathrm{X} 3$ & $\mathrm{X} 4$ & X5 & X6 & X7 & X8 & X9 & X 10 & X 11 & X 12 & $\begin{array}{c}X \\
13\end{array}$ & $\begin{array}{c}X \\
14\end{array}$ & $\begin{array}{l}X \\
15\end{array}$ & $\begin{array}{c}X \\
16\end{array}$ & D1 & D2 & D3 \\
\hline 1 & + & + & - & - & + & + & + & + & - & + & - & + & - & - & - & - & + & + & - \\
\hline 2 & - & + & + & - & - & + & + & + & + & - & + & - & + & - & - & - & - & + & + \\
\hline 3 & + & - & + & + & - & - & + & + & + & + & - & + & - & + & - & - & - & - & + \\
\hline 4 & + & + & - & + & + & - & - & + & + & + & + & - & + & - & + & - & - & - & - \\
\hline 5 & - & + & + & - & + & + & - & - & + & + & + & + & - & + & - & + & - & - & - \\
\hline 6 & - & - & + & + & - & + & + & - & - & + & + & + & + & - & + & - & + & - & - \\
\hline 7 & - & - & - & + & + & - & + & + & - & - & + & + & + & + & - & + & - & + & - \\
\hline 8 & - & - & - & - & + & + & - & + & + & - & - & + & + & + & + & - & + & - & + \\
\hline 9 & + & - & - & - & - & + & + & - & + & + & - & - & + & + & + & + & - & + & - \\
\hline 10 & - & + & - & - & - & - & + & + & - & + & + & - & - & + & + & + & + & - & + \\
\hline 11 & + & - & + & - & - & - & - & + & + & - & + & + & - & - & + & + & + & + & - \\
\hline 12 & - & + & - & + & - & - & - & - & + & + & - & + & + & - & - & + & + & + & + \\
\hline 13 & + & - & + & - & + & - & - & - & - & + & + & - & + & + & - & - & + & + & + \\
\hline 14 & + & + & - & + & - & + & - & - & - & - & + & + & - & + & + & - & - & + & + \\
\hline 15 & + & + & + & - & + & - & + & - & - & - & - & + & + & - & + & + & - & - & + \\
\hline 16 & + & + & + & + & - & + & - & + & - & - & - & - & + & + & - & + & + & - & - \\
\hline 17 & - & + & + & + & + & - & + & - & + & - & - & - & - & + & + & - & + & + & - \\
\hline 18 & - & - & + & + & + & + & - & + & - & + & - & - & - & - & + & + & - & + & + \\
\hline 19 & + & - & - & + & + & + & + & - & + & - & + & - & - & - & - & + & + & - & + \\
\hline 20 & - & - & - & - & - & - & - & - & - & - & - & - & - & - & - & - & - & - & - \\
\hline
\end{tabular}

